\title{
Shikonin stimulates MC3T3-E1 cell proliferation and differentiation via the BMP-2/Smad5 signal transduction pathway
}

\author{
TAO FANG ${ }^{1}$, QIANQIAN WU ${ }^{2}$, SHUAI MU ${ }^{1}$, \\ LIYU YANG $^{1}$, SHENGYE LIU ${ }^{1}$ and QIN FU ${ }^{1}$ \\ ${ }^{1}$ Department of Orthopedic Surgery, Shengjing Hospital of China Medical University; \\ ${ }^{2}$ Department of Cardiology, First Affiliated Hospital of China Medical University, Shenyang, Liaoning 110000, P.R. China
}

Received August 12,2015; Accepted May 10, 2016

DOI: $10.3892 / \mathrm{mmr} .2016 .5363$

\begin{abstract}
Shikonin, the predominant naphthoquinone pigment isolated from the Chinese plant Lithospermum erythrorhizon, is anti-inflammatory, antiviral and exerts anticancer effects, amongst other biological activities. However, it is unknown whether shikonin affects bone formation. In the present study, the role of shikonin on cell proliferation was assessed via MTT assay, and shikonin was identified to markedly promote cell growth in a time- and dose-dependent manner in the MC3T3-E1 cell line. In addition, flow cytometric analysis was performed to evaluate the effect of shikonin on the cell cycle, and it was observed that shikonin markedly increased the percentage of S-phase MC3T3-E1 cells to accelerate the $G_{1} / S$ transition. To investigate the potential molecular mechanism by which shikonin enhances bone formation, the changes in bone morphogenic protein-2 (BMP-2), SMAD family member 5 (Smad5), runt related transcription factor 2 (Runx2), alkaline phosphatase (ALP) and osteocalcin (OC) expression levels induced by shikonin were investigated using western blot analysis and quantitative polymerase chain reaction. The results indicated that shikonin increased the BMP-2 and Smad5 mRNA levels, and upregulated Smad5 and Runx2 protein expression levels to promote osteoblast differentiation. Furthermore, ALP staining was performed, and revealed that shikonin enhanced ALP activity. These results indicate that shikonin promotes cell proliferation and differentiation of MC3T3-E1 cells via the BMP-2/Smad5 signaling pathway.
\end{abstract}

Correspondence to: Professor Qin Fu, Department of Orthopedic Surgery, Shengjing Hospital of China Medical University, 36 Sanhao, Street Shenyang, Liaoning 110000, P.R. China

E-mail: qinfusj@163.com

Key words: shikonin, osteoporosis, bone formation, MC3T3-E1 cells

\section{Introduction}

Osteoporosis is a serious public health issue that is characterized by a reduction of bone mass, which is caused by an imbalance between bone resorption and bone formation (1). Osteoporosis affects numerous individuals throughout the world $(2,3)$; however, currently there are no effective and economical therapeutic strategies to cure osteoporosis (4). Therefore, establishing a novel therapeutic agent for the prevention and treatment of osteoporosis is considered to be critical. Traditional Chinese medicine has become the focus of basic research and clinical studies due to reduced side-effects when compared with cytokine and hormone therapy (5).

Shikonin (5,8-dihydroxy-2-[(1S)-1-hydroxy-4-methyl pent-3-en-1-yl] naphthalene-1,4-dione), is a predominant type of naphthoquinone pigment that is extracted from the Chinese plant, Lithospermum erythrorhizon (6), with a molecular weight of 288 (Fig. 1). Shikonin performs many biological activities; it is an antioxidant, anti-inflammatory, antithrombotic, antiviral, and antimicrobial, it has anticancer properties and is associated with accelerated wound healing $(7,8)$. Previous studies have demonstrated that shikonin inhibits cell growth, mediates cell apoptosis and alters the cell cycle in various types of tumor cell $(9,10)$. However, whether shikonin exerts an effect on bone formation remains unknown. Therefore, the aim of the present study was to investigate the possible influence and associated mechanisms of shikonin on MC3T3-E1 cell proliferation and differentiation.

Many studies have demonstrated that bone morphogenetic proteins (BMPs) and transforming growth factor- $\beta$ (TGF- $\beta$ ) are the most important cytokines affecting the proliferation, differentiation and function of osteoblasts $(11,12)$. BMP-2, a member of the TGF- $\beta$ superfamily, is a key signaling component in osteoblast proliferation and differentiation $(13,14)$. SMAD family member 5 (Smad5) is a downstream transcription factor that is phosphorylated and activated by the receptors of BMP-2. Phosphorylated Smad5 forms a complex with Smad4 (co-Smad), and translocates into the nucleus to activate the transcription factor, runt related transcription factor 2 (Runx2) $(15,16)$. The BMP-2/Smad5 signal transduction pathway is important in osteoblast proliferation and differentiation. In the present study, the function of shikonin on 
biological behaviors of MC3T3-E1 cells, such as cell growth, cell division and ALP activity were assessed. In addition, the potent mechanism of shikonin-enhanced bone formation was investigated by examining the expression levels of BMP-2, Smad5, Runx2, alkaline phosphatase (ALP) and osteocalcin $(\mathrm{OC})$ in the MC3T3-E1 cell line.

\section{Materials and methods}

Materials and reagents. Purified shikonin (>98\%) was purchased from the National Institute for the Control Pharmaceutical and Biological Products (Beijing, China). Shikonin was dissolved in dimethyl sulfoxide (DMSO; Sigma-Aldrich, St. Louis, MO, USA) and stored at $-20^{\circ} \mathrm{C}$. The final concentrations of shikonin were 0 (control), 10, 50 and $100 \mathrm{ng} / \mathrm{ml}$, and the final concentration of DMSO in the culture was $<0.01 \%$. $\alpha$-Minimum Essential Medium ( $\alpha$-MEM), fetal bovine serum (FBS) and trypsin-EDTA were obtained from GE Healthcare Life Sciences (Hyclone; Logan, UT, USA). 3-(4,5-dimethylthiazol-2-yl)-2,5-diphenyltetrazolium bromide (MTT) was purchased from Sigma-Aldrich. Rabbit anti-Smad5 (cat. no. ab13724), mouse anti-Runx2 (cat. no. ab76956) and mouse anti-GAPDH (cat. no. ab8245) monoclonal antibodies of were purchased from Abcam (Cambridge, MA, USA). Invitrogen TRIzol reagent was obtained from Thermo Fisher Scientific, Inc. (Waltham, MA, USA). Primers were designed and synthesized by Sangon Biotech Co., Ltd. (Shanghai, China).

Cell culture. The MC3T3-E1 cells were purchased from the Cell Center of the Chinese Academy of Medical Sciences (Shanghai, China) and cultured in $\alpha$-MEM containing 10\% FBS and $100 \mathrm{U} / \mathrm{ml}$ penicillin and $100 \mu \mathrm{g} / \mathrm{ml}$ streptomycin in $5 \% \mathrm{CO}_{2}$ at $37^{\circ} \mathrm{C}$. The medium was replaced every 3 days, and the cells were subcultured using $0.25 \%$ trypsin with $0.01 \%$ EDTA.

Cell proliferation assay. The effect of shikonin on cell proliferation was evaluated using the MTT assay. The cells were seeded in 96-well plates at a density of $1.0 \times 10^{3}$ cells/well. Following incubation for $24 \mathrm{~h}$ at $37^{\circ} \mathrm{C}$, the cells were treated with various final concentrations $(0,10,50$ and $100 \mathrm{ng} / \mathrm{ml})$ of shikonin. Cells were treated with $20 \mu \mathrm{l}$ MTT $(5 \mathrm{mg} / \mathrm{ml})$ during the final $4 \mathrm{~h}$ of the culture and the optical density of the wells was measured at $490 \mathrm{~nm}$ using a microplate reader.

Cell cycle assay. MC3T3-E1 cells $\left(1 \times 10^{5}\right.$ cells $\left./ \mathrm{ml}\right)$ were plated in four tissue culture flasks. After $24 \mathrm{~h}$, cells were treated with various concentrations of shikonin $(0,10,50$ and $100 \mathrm{ng} / \mathrm{ml})$ for $48 \mathrm{~h}$. Then, cells were harvested, fixed in $70 \%$ ethanol for $12 \mathrm{~h}$, washed with phosphate-buffered saline (PBS) and stained in $5 \mathrm{mg} / \mathrm{ml}$ propidium iodide in PBS supplemented with RNase A (Roche Diagnostics, Indianapolis, IN, USA) for $30 \mathrm{~min}$ at room temperature. Data were analyzed using CellQuest v3.3 (BD Biosciences, San Jose, CA, USA).

Reverse transcription-quantitative polymerase chain reaction $(R T-q P C R)$. After $48 \mathrm{~h}$ of shikonin treatment, total RNA was extracted with TRIzol reagent. Then total RNA was used to synthesize cDNA using SuperScript II reverse transcriptase (Invitrogen; Thermo Fisher Scientific, Inc.) with $5 \mu \mathrm{g}$ oligo (dT) primers per sample. qPCR was performed using SYBR

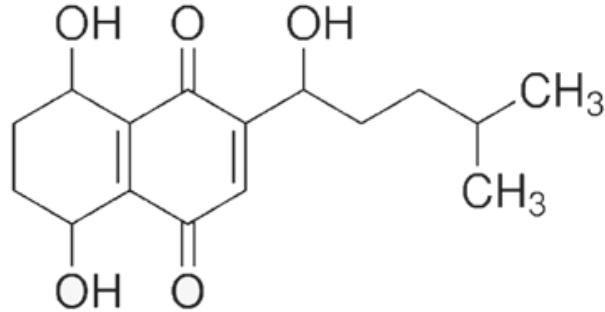

Figure 1. Chemical structure of shikonin.

Green PCR master mix (Applied Biosystems; Thermo Fisher Scientific, Inc.) in a total volume of $20 \mu 1$ using a 7900HT Fast Real-Time PCR System (Applied Biosystems; Thermo Fisher Scientific, Inc.) as follows: $95^{\circ} \mathrm{C}$ for $30 \mathrm{sec}$, and 40 cycles of $95^{\circ} \mathrm{C}$ for $5 \mathrm{sec}$ and $60^{\circ} \mathrm{C}$ for $30 \mathrm{sec}$. A dissociation step was performed to generate a melting curve to confirm the specificity of the amplification and GAPDH served as the reference gene. The relative levels of gene expression were represented as $\Delta \mathrm{Cq}=\mathrm{Cq}_{\text {gene }}-\mathrm{Cq}_{\text {reference }}$, and the fold change of gene expression was calculated according to the $2^{-\Delta \Delta \mathrm{Cq}}$ method (17). Experiments were repeated in triplicate. The primer sequences were as follows: Forward, 5'-GCTGGTCACAGATAAGGC CA-3' and reverse, 5'-TTTCTCGTTTGTGGAGCGGA-3' for BMP-2; forward, 5'-GTGAAGCGATTGTTGGGCTG-3' and reverse 5'-CAGGTGGCATATAGGCAGGG-3' for Smad5; forward, 5'-GCGCATTCCTCATCCCAGTA-3' and reverse, 5'-AGTTCTGAAGCACCTGCCTG-3' for Runx2; forward, 5'-TGACCTTCTCTCCTCCATCC-3' and reverse, 5'-CTT CCTGGGAGTCTCATCCT-3' for ALP; forward, 5'-TGC TTGTGACGAGCTATCAG-3' and reverse, 5'-GAGGACAGG GAGGATCAAGT-3' for OC; and forward, 5'-GTGAAGCAG GCATCTGAGGG-3' and reverse, 5'-GCCGTATTCATTGTC ATACCAGG-3' for GAPDH.

Western blot analysis. Total proteins from cell lines were harvested in lysis buffer (Thermo Fisher Scientific, Inc.) and quantified according to the Bradford method. Fifty micrograms of protein were separated by SDS-PAGE (12\%) at a constant voltage (110V) for $2 \mathrm{~h}$, and transferred onto a polyvinylidene difluoride membrane. The membranes were blocked in 5\% nonfat dry milk diluted with Tris-buffered saline Tween-20 [TBST; $20 \mathrm{mmol} / \mathrm{l}$ Tris- $\mathrm{HCl}, 150 \mathrm{mmol} / \mathrm{l} \mathrm{NaCl}$ (PH 7.5 ) and $0.1 \%$ Tween 20] at room temperature for $1 \mathrm{~h}$. Samples were incubated overnight at $4^{\circ} \mathrm{C}$ with monoclonal antibodies against Smad5 (1:1,000), Runx2 (1:1,000) and GAPDH $(1: 1,000)$ followed by incubation for $2 \mathrm{~h}$ with a goat-anti rabbit peroxidase-conjugated IgG (cat. no. ab6721; Abcam; 1:1,000) and anti-mouse horseradish peroxidase-conjugated IgG (cat. no. ab131368; Abcam; 1:1,000). The bound proteins were visualized using enhanced chemiluminescence (Thermo Fisher Scientific, Inc.) and detected using a BioImaging System (UVP Inc., Upland, CA, USA). The relative protein levels were calculated based on GAPDH as the loading control.

ALP staining. To observe the influence of shikonin on osteoblast differentiation, staining of ALP (an early maker of osteoblast differentiation) was performed. Cells $\left(2 \times 10^{5}\right.$ cells/well) were plated and cultured in 6-well plates for 


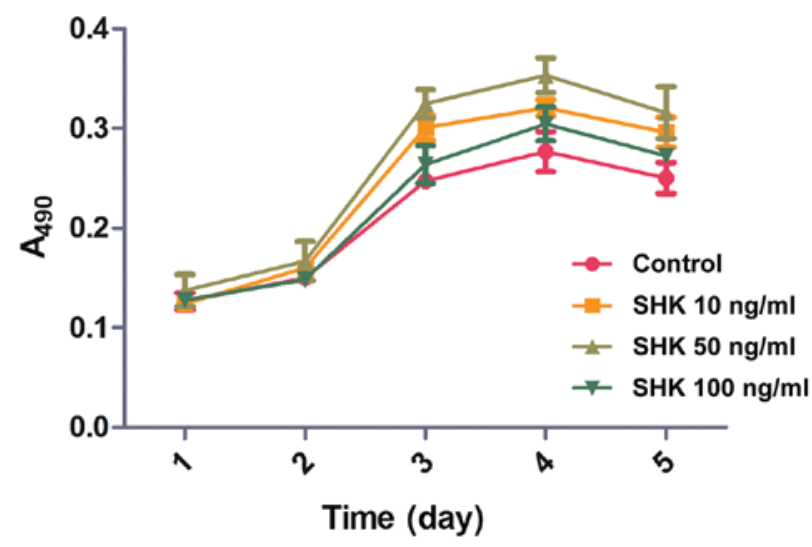

Figure 2. Influence of shikonin on MC3T3-E1 cell growth curves. Cells were exposed to 0 (control), 10, 50, $100 \mathrm{ng} / \mathrm{ml}$ SHK. The MTT assay indicates that shikonin may stimulate cell proliferation, particularly in the $50 \mathrm{ng} / \mathrm{ml}$ group on day 4 . SHK, shikonin.

A

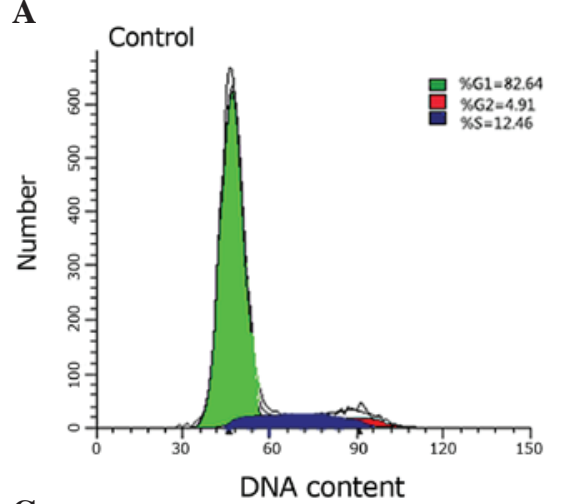

C

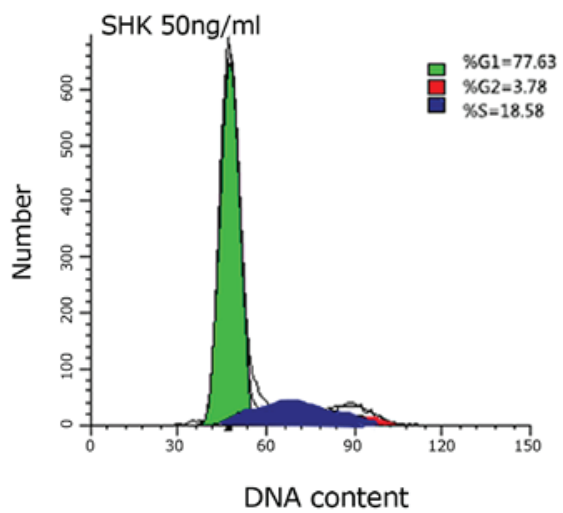

B

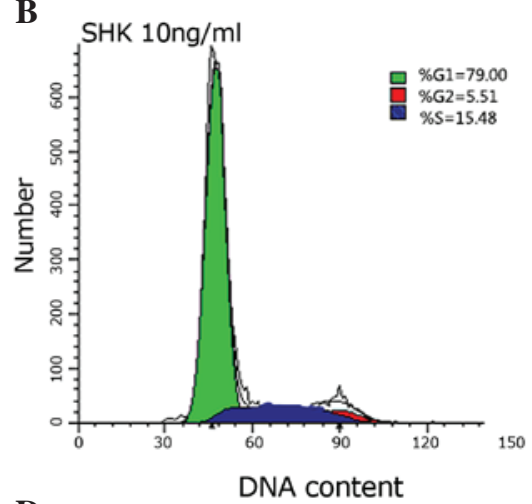

D

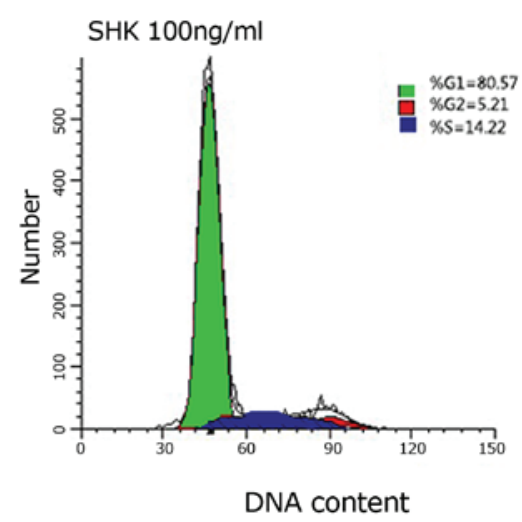

Figure 3. Effect of (A) 0, (B) 10, (C) 50 and (D) $100 \mathrm{ng} / \mathrm{ml} \mathrm{SHK}$ on the cell cycle in MC3T3-E1 cells. Flow cytometry demonstrated that shikonin promotes cell cycle progression. SHK, shikonin; concent, concentration.

$24 \mathrm{~h}$ at $37^{\circ} \mathrm{C}$, and treated with 0 (control), 10,50, $100 \mathrm{ng} / \mathrm{ml}$ shikonin. The medium was replaced every 3 days. A week later, cells were washed three times with PBS and fixed in $10 \%$ paraformaldehyde for $10 \mathrm{~min}$ at $25^{\circ} \mathrm{C}$. The cells were stained using $300 \mu \mathrm{g} / \mathrm{ml}$ 5-bromo-4-chloro-3-indolyl phosphate/nitroblue tetrazolium buffer (Thermo Fisher Scientific, Inc.) for $20 \mathrm{~min}$ at $25^{\circ} \mathrm{C}$. ALP-positive cells were stained blue/purple. The stained cells were visualized using a digital microscope (DP73; Olympus, Tokyo, Japan).

Statistical analysis. All statistical analysis were performed using GraphPad Prism 5.0 (GraphPad Software, Inc., La Jolla,
CA, USA). Data were presented as the mean \pm standard error of the mean, and statistically analyzed using a two-tailed Student's $t$ test and one-way analysis of variance. $\mathrm{P}<0.05$ was considered to indicate a statistically significant difference.

\section{Results}

Shikonin stimulates cell proliferation. The effects of different concentrations of shikonin on the proliferation of MC3T3-E1, following 24, 48, 72, 96 and $120 \mathrm{~h}$ treatments, were examined by MTT (Fig. 2) to examine whether shikonin stimulates MC3T3-E1 cell proliferation in vitro. During the initial 
A

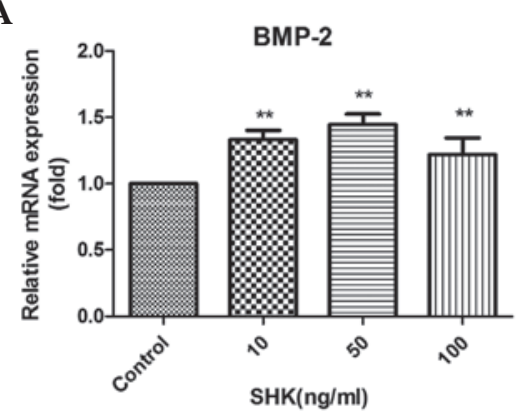

C

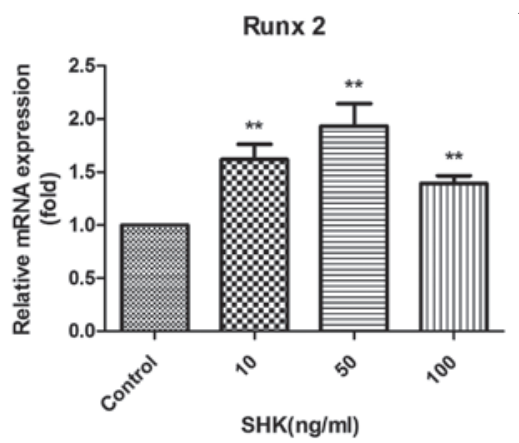

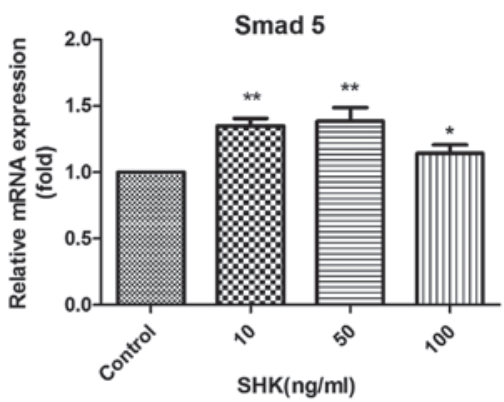

D

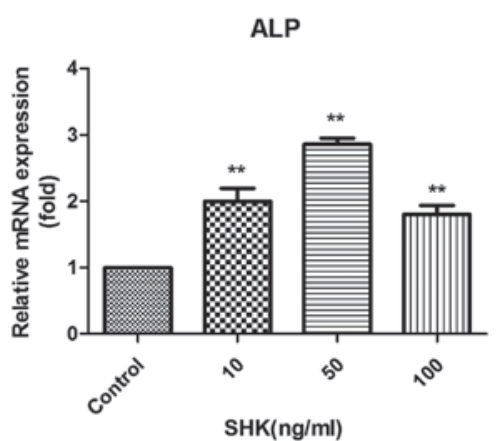

E

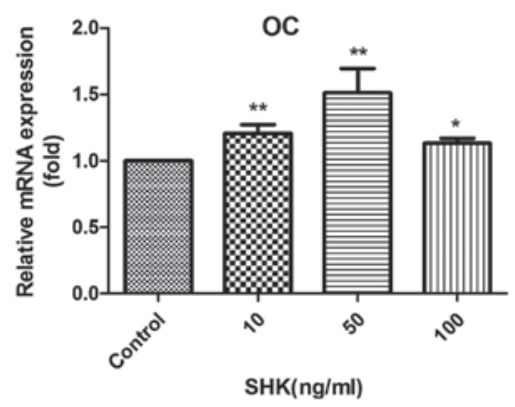

Figure 4. Effect of SHK on (A) BMP-2, (B) Smad5, (C) Runx2, (D) ALP and (E) OC mRNA expression levels in the MC3T3-E1 cells. Each experiment was performed in triplicate and data are presented as the mean \pm standard deviation. ${ }^{*} \mathrm{P}<0.05$ and ${ }^{* *} \mathrm{P}<0.01$ vs. control. SHK, shikonin; BMP-2, bone morphogenic protein-2; Smad5, SMAD family member 5; Runx2, runt related transcription factor 2; ALP, alkaline phosphatase; OC, osteocalcin.

2 days, no statistically significant differences in MC3T3-E1 cell viability were observed between the groups. However, compared with the control and the $100 \mathrm{ng} / \mathrm{ml}$ shikonin group, a marginally greater quantity of cells were observed in the 10 and $50 \mathrm{ng} / \mathrm{ml}$ shikonin groups on day 3 and 4 . On day 4, the speed of cell proliferation peaked in the $50 \mathrm{ng} / \mathrm{ml}$ shikonin group and declined thereafter. These results demonstrated that shikonin treatment promotes MC3T3-E1 cell proliferation.

Shikonin stimulates cell division. Subsequently, cell cycle analysis was performed to assess the effect of shikonin on MC3T3-E1 cell cycle progression. As shown in Fig. 3, MC3T3-E1 cells treated with 10,50 and $100 \mathrm{ng} / \mathrm{ml}$ shikonin exhibited increased percentages of S-phase cells, particularly in the $50 \mathrm{ng} / \mathrm{ml}$ shikonin groups. These data indicate that certain concentrations of shikonin accelerate cell cycle progression.

Effects of shikonin on BMP-2, SMAD5, Runx2, ALP and OC mRNA expression levels. Total mRNA was extracted after MC3T3-E1 cells were treated with $0,10,50$ or $100 \mathrm{ng} / \mathrm{ml}$ shikonin for $48 \mathrm{~h}$, and the mRNA expression levels of BMP-2,

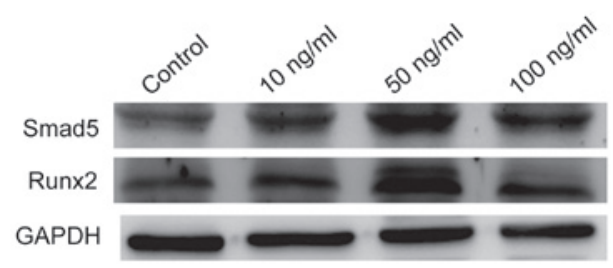

Figure 5. Effect of shikonin on Smad5 and Runx2 protein expression in MC3T3-E1 cells. The cells were treated with or without shikonin for $48 \mathrm{~h}$. Western blot analysis demonstrated that different concentrations of shikonin (10, 50 and $100 \mathrm{ng} / \mathrm{ml}$ ) markedly increased Smad5 and Runx2 expression compared with the control, particularly in the $50 \mathrm{ng} / \mathrm{ml}$ group. Cells treated with $0 \mathrm{ng} / \mathrm{ml}$ shikonin served as the controls. Smad5, SMAD family member 5; Runx2, runt related transcription factor 2.

Smad5, Runx2, ALP and OC were detected by RT-qPCR. The BMP-2, Smad5, Runx2, ALP and OC expression level in the cells treated with 10,50 and $100 \mathrm{ng} / \mathrm{ml}$ shikonin increased significantly compared with the untreated control cells $(\mathrm{P}<0.01, \mathrm{P}<0.05, \mathrm{P}<0.01, \mathrm{P}<0.01$ and $\mathrm{P}<0.05$, respectively) (Fig. 4). In addition, the expression levels of BMP-2, Smad5, Runx2, ALP and OC were increased to the highest levels in 

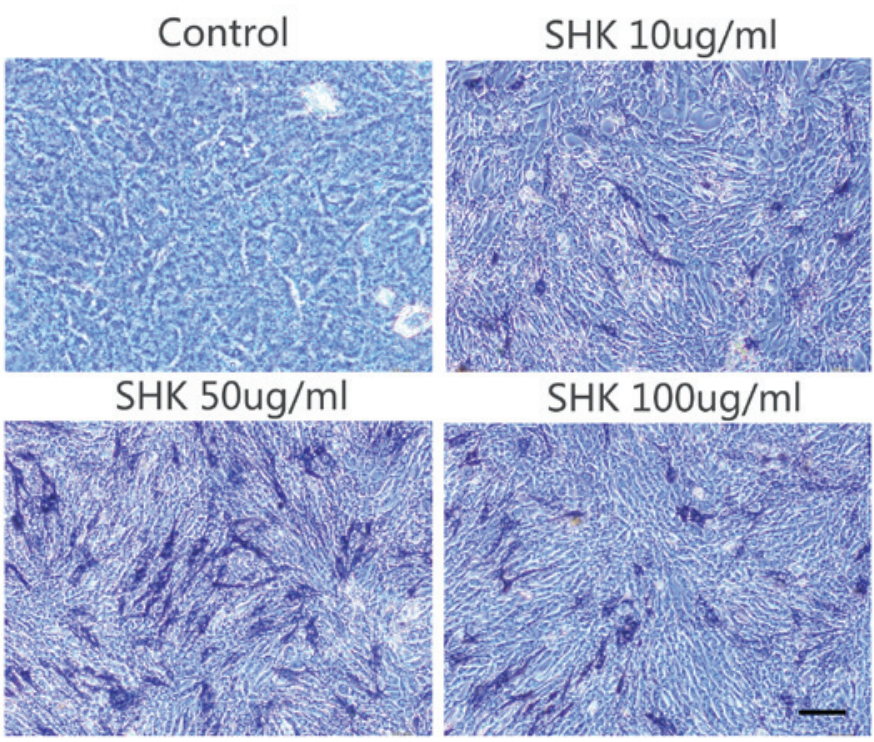

Figure 6. Effect of SHK on ALP activity in MC3T3-E1 cells. The MC3T3-E1 cells were treated with or without SHK for 7 days. The ALP activity was examined by ALP staining. ALP-positive cells were stained blue/purple. Treatment with 10, 50, $100 \mathrm{ng} / \mathrm{ml} \mathrm{SHK}$ enhanced the ALP activity, markedly more so than that of the control, particularly in the $50 \mathrm{ng} / \mathrm{ml}$ group. Cells treated with $0 \mathrm{ng} / \mathrm{ml}$ SHK served as controls. Scale bar, $200 \mu \mathrm{m}$. SHK, shikonin; ALP, alkaline phosphatase.

the $50 \mathrm{ng} / \mathrm{ml}$ shikonin group. This demonstrated that shikonin promotes osteoblast differentiation via its effect on BMP-2, SMAD5, Runx2, ALP and OC expression levels.

Effects of shikonin on Smad5 and Runx2 protein expression levels. To further investigate the mechanism by which shikonin stimulates osteoblast differentiation, western blotting was performed to examine the shikonin-induced changes in Smad5 and Runx2 protein expression (Fig. 5). Different concentrations of shikonin $(10,50$ and $100 \mathrm{ng} / \mathrm{ml})$ markedly increased Smad5 and Runx2 protein expression levels in the MC3T3-E1 cells compared with the control cells, particularly in the $50 \mathrm{ng} / \mathrm{ml}$ group. These findings revealed that shikonin regulates the expression levels of Smad5 and Runx2 proteins, which influences osteoblastic differentiation.

Effects of shikonin on ALP activity. The ALP activity in the MC3T3-E1 cells was examined by ALP histochemical staining 7 days after treatments with $0,10,50$ or $100 \mathrm{ng} / \mathrm{ml}$ shikonin. The results demonstrate that treatment with different concentrations of shikonin elicits significantly greater ALP activity when compared with the control group (Fig. 6), particularly in the $50 \mathrm{ng} / \mathrm{ml}$ group. These results indicate that shikonin enhanced the activity of ALP in MC3T3-E1 cells.

\section{Discussion}

In the present study, the osteoprotective effects of shikonin and its potential mechanism in MCET3-E1 cells were examined. The results clearly demonstrated that treatment with 10 , 50 and $100 \mathrm{ng} / \mathrm{ml}$ of shikonin, particularly $50 \mathrm{ug} / \mathrm{ml}$ shikonin, enhances cell viability, stimulates cell cycle progression, resulting in a greater number of cells in the S-phase, and promotes ALP activity in MC3T3-E1 cells. Additionally, shikonin upregulated the expression levels of BMP-2, Smad5, Runx2, ALP and OC, indicating that the BMP-2/Smad5 signal transduction pathway may be involved in shikonin-induced cell proliferation and differentiation.

Osteoporosis, a progressive disorder of aging bones, is widely recognized as a major public health issue (18). Bone is a dynamic tissue, which is mediated by the balance between osteoblastic bone formation and osteoclastic bone resorption (19). Osteoblasts, osteoclasts, and osteocytes are important in bone generation, maintenance and remodeling (20). Multiple factors, which cause the imbalance of osteoblasts and osteoclasts at the bone remodeling process, result in the loss of bone mass (21). Hence, therapeutic agents that increase the activity of osteoblasts may be administered to treat osteoporosis.

Due to fewer associated side-effects, Chinese herbs require investigation to identify more effective therapeutic agents that promote osteoblast proliferation and differentiation. Shikonin has attracted increasing attention, as it exhibits numerous biological activities, such as anti-inflammatory, antiviral and anti-cancer actions (22-24). Hence, the effects of shikonin on MC3T3-E1 cells were evaluated in the current study.

The results of the study confirm that shikonin promotes the proliferation of MC3T3-E1 cells in a dose- and time-dependent manner. The rate of cell proliferation peaked in response to $50 \mathrm{ng} / \mathrm{ml}$ shikonin on day 4 and decreased thereafter. Furthermore, the percentage of S-phase cells in the $50 \mathrm{ng} / \mathrm{ml}$ shikonin group was the greatest, which suggests active DNA synthesis and cell proliferation. Therefore, shikonin may lead to osteogenesis by stimulating osteoblast proliferation.

Numerous studies have demonstrated that TGF- $\beta$ and BMPs are the most important cytokines affecting the proliferation, differentiation and function of osteoblasts $(11,12)$. BMP-2 is a member of the TGF- $\beta$ superfamily. Various studies have demonstrated that BMP-2 is a key signaling component in the regulation of bone induction, repair and maintenance (25-27). Smad5 is the intracellular mediator of BMP-2 and may be phosphorylated by heterotetrameric serine/threonine kinase receptors of BMP-2 (28). After 
forming a complex with Smad4, phosphorylated Smad5 entered into the nucleus, activating the transcription factors of Runx2 $(15,16)$. Our results indicated that the levels BMP-2, Smad5, Runx2, ALP and OC expression increased in shikonin-treated MC3T3-E1 cells, particularly in the $50 \mathrm{ng} / \mathrm{ml}$ group.

ALP is an early maker of osteoblast differentiation, thus, the effects of shikonin on ALP activity were detect by ALP staining. The results demonstrated that treatment with shikonin enhanced ALP activity, particularly in the $50 \mathrm{ng} / \mathrm{ml}$ group, suggesting that shikonin promotes osteoblast differentiation.

Shikonin, an active ingredient isolated from the Chinese plant, Lithospermum erythrorhizon, is widely administered as a traditional Chinese medicine to treat certain diseases, such as wet typhus, purpura, eczema and erysipelas. The present study demonstrates that shikonin stimulates MC3T3-E1 cell proliferation and differentiation via the BMP-2/Smad5 signaling pathway.

In conclusion, in addition to the anti-inflammatory, antiviral and anti-cancer effects of shikonin, the present study is the first, to the best of our knowledge, to demonstrate that shikonin stimulates osteoblast proliferation and differentiation. Therefore, shikonin may present as a novel and potent candidate for the management of osteoporosis. However, further investigations are required to reveal the mechanism by which shikonin acts to promote bone formation.

\section{Acknowledgements}

This study was supported by grants from the National Nature Science Foundation of China (grant nos. 81370981 and 31201053) and the Outstanding Scientific Fund of Shengjing Hospital.

\section{References}

1. Bone H: Future directions in osteoporosis therapeutics. Endocrinol Metab Clin North Am 41: 655-661, 2012.

2. Sharma L, Kapoor D and Issa S: Epidemiology of osteoarthritis: An update. Curr Opin Rheumatol 18: 147-156, 2006.

3. Lane NE: Epidemiology, etiology, and diagnosis of osteoporosis. Am J Obstet Gynecol 194 (2 Suppl): S3-S11, 2006.

4. Kobayashi Y, Uehara S, Koide M and Takahashi N: The regulation of osteoclast differentiation by Wnt signals. Bonekey Rep 4: 713, 2015.

5. Zhou H, Wang S, Xue Y and Shi N: Regulation of the levels of Smad1 and Smad5 in MC3T3-E1 cells by Icariine in vitro. Mol Med Rep 9: 590-594, 2014.

6. Andújar I, Rios JL, Giner RM and Recio MC: Pharmacological properties of shikonin-a review of literature since 2002. Planta Med 79: 1685-1697, 2013.

7. Chen X, Yang L, Oppenheim JJ and Howard MZ: Cellular pharmacology studies of shikonin derivatives. Phytother Res 16 199-209, 2002

8. Wang Y, Zhou Y, Jia G, Han B, Liu J, Teng Y, Lv J, Song Z, Li Y, Ji L, et al: Shikonin suppresses tumor growth and synergizes with gemcitabine in a pancreatic cancer xenograft model: Involvement of NF-kB signaling pathway. Biochem Pharmacol 88: 322-333, 2014.

9. Han W, Li L, Qiu S, Lu Q, Pan Q, Gu Y, Luo J and Hu X: Shikonin circumvents cancer drug resistance by induction of a necroptotic death. Mol Cancer Ther 6: 1641-1649, 2007.
10. Chang IC, Huang YJ, Chiang TI, Yeh CW and Hsu LS: Shikonin induces apoptosis through reactive oxygen species/extracellular signal-regulated kinase pathway in osteosarcoma cells. Biol Pharm Bull 33: 816-824, 2010.

11. Knoll BI,McCarthy TL, Centrella M and Shin J: Strain-dependent control of transforming growth factor-beta function in osteoblasts in an in vitro model: Biochemical events associated with distraction osteogenesis. Plast Reconstr Surg 116: 224-233, 2005.

12. Fagenholz PJ, Warren SM, Greenwald JA, Bouletreau PJ, Spector JA, Crisera FE and Longaker MT: Osteoblast gene expression is differentially regulated by TGF-beta isoforms. J Craniofac Surg 12: 183-190, 2001.

13. Cao H, Ke Y, Zhang Y, Zhang CJ, Qian W and Zhang GL: Icariin stimulates MC3T3-E1 cell proliferation and differentiation through up-regulation of bone morphogenetic protein-2. Int J Mol Med 29: 435-439, 2012.

14. Liang W, Lin M, Li X, Li C, Gao B, Gan H, Yang Z, Lin X, Liao $\mathrm{L}$ and Yang $\mathrm{M}$ : Icariin promotes bone formation via the BMP-2/Smad4 signal transduction pathway in the hFOB 1.19 human osteoblastic cell line. Int J Mol Med 30: 889-895, 2012.

15. Cheng H, Jiang W, Phillips FM, Haydon RC, Peng Y, Zhou L, Luu HH, An N, Breyer B, Vanichakarn P, et al: Osteogenic activity of the fourteen types of human bone morphogenetic proteins (BMPs). J Bone Joint Surg Am 85-A: 1544-1552, 2003.

16. Ghosh-Choudhury N, Singha PK, Woodruff K, St Clair P, Bsoul S, Werner SL and Choudhury GG: Concerted action of Smad and CREB-binding protein regulates bone morphogenetic protein-2-stimulated osteoblastic colony-stimulating factor-1 expression. J Biol Chem 281: 20160-20170, 2006.

17. Livak KJ and Schmittgen TD: Analysis of relative gene expression data using real-time quantitative PCR and the 2(-Delta Delta C(T)) Method. Methods 25: 402-408, 2001

18. Hiligsmann M, Vanoverberghe $\mathrm{M}$, Neuprez $\mathrm{A}$, Bruyère $\mathrm{O}$ and Reginster JY: Cost-effectiveness of strontium ranelate for the prevention and treatment of osteoporosis. Expert Rev Pharmacoecon Outcomes Res 10: 359-366, 2010.

19. Compston J: Osteoporosis: Social and economic impact. Radiol Clin North Am 48: 477-482, 2010

20. Swarnkar G, Sharan K, Siddiqui JA, Chakravarti B, Rawat P, Kumar M, Arya KR, Maurya R and Chattopadhyay N: A novel flavonoid isolated from the steam-bark of Ulmus Wallichiana Planchon stimulates osteoblast function and inhibits osteoclast and adipocyte differentiation. Eur J Pharmacol 658: 65-73, 2011.

21. Tabuchi M, Miyazawa K, Kimura M, Maeda H, Kawai T, Kameyama Y and Goto S: Enhancement of crude bone morphogenetic protein-induced new bone formation and normalization of endochondral ossification by bisphosphonate treatment in osteoprotegerin-deficient mice. Calcif Tissue Int 77: 239-249, 2005.

22. Chen X, Yang L, Zhang N, Turpin JA, Buckheit RW, Osterling C, Oppenheim JJ and Howard OM: Shikonin, a component of Chinese herbal medicine, inhibits chemokine receptor function and suppresses human immunodeficiency virus type 1. Antimicrob Agents Chemother 47: 2810-2816, 2003.

23. Yeh CC, Kuo HM, Li TM, Lin JP, Yu FS, Lu HF, Chung JG and Yang JS: Shikonin-induced apoptosis involves caspase-3 activity in a human bladder cancer cell line (T24). In Vivo 21: 1011-1019, 2007.

24. Wiench B, Eichhorn T, Paulsen M and Efferth T: Shikonin directly targets mitochondria and causes mitochondrial dysfunction in cancer cells. Evid Based Complement Alternat Med 2012: 726025, 2012.

25. Kamiya N, Ye L, Kobayashi T, Mochida Y, Yamauchi M, Kronenberg HM, Feng JQ and Mishina Y: BMP signaling negatively regulates bone mass through sclerostin by inhibiting the canonical Wnt pathway. Development 135: 3801-3811, 2008.

26. Yoshida Y, Tanaka S, Umemori H, Minowa O, Usui M, Ikematsu N, Hosoda E, Imamura T, Kuno J, Yamashita T, et al: Negative regulation of BMP/Smad signaling by Tob in osteoblasts. Cell 103: 1085-1097, 2000.

27. Harada S and Rodan GA: Control of osteoblast function and regulation of bone mass. Nature 423: 349-355, 2003.

28. Wang L, Zhang X, Guo Y, Chen X, Li R, Liu L, Shi C, Guo C and Zhang Y: Involvement of BMPs/Smad signaling pathway in mechanical response in osteoblasts. Cell Physiol Biochem 26: 1093-1102, 2010 